\title{
High Sensitivity Spring Coil as Displacement Sensor for Slope Stability Monitoring
}

\author{
Hafizh Prihtiadi ${ }^{\mathrm{a}}$, Mitra Djamal ${ }^{\mathrm{a}, \mathrm{b}^{*}}$ \\ ${ }^{a}$ Theoretical High Energy Physics and Instrumentation Research Division, Faculty of Mathematics and Natural \\ Sciences, Institut Teknologi Bandung, Jl. Ganesa no. 10, Bandung 40132, Indonesia \\ ${ }^{b}$ Department of Physics, Institut Teknologi Sumatera, Jl. Terusan Jenderal Ryacudu, Lampung Selatan 35365, Indonesia \\ *Corresponding Author: mitra@fi.itb.ac.id
}

\begin{abstract}
Landslide monitoring often includes observing in two conditions, slope movements and groundwater levels. This measurement involves the observation of deformation direction. However, the range and reliability of current slope stability monitoring are often limited on sensors, instrumentation costs, and power requirements. This paper presents an attractive solution for slope stability monitoring that aims to be inexpensive, versatile, and reliable. A displacement sensor based on spring coil as an actuator was build and tested for slope deformation and potential failures. The inductance of spring coil will change when deformed (compression or strain) and the physical quantity that can be measured. It has a long $1.2 \mathrm{~m}$, diameter $3 \mathrm{~cm}$, and 80 turns. The electronic systems consist of LC oscillator, comparator, universal frequency to digital converter (UFDC), and ADC. The output voltage of sensor has a maximum measurement of $0.43 \mathrm{~V}$ up to $4.48 \mathrm{~V}$ and frequency oscillation between $583 \mathrm{kHz}$ up to $1.853 \mathrm{MHz}$. This sensor can detect a small deformation of the ground with a relative error under $5 \%$ and an absolute error under 3 $\mathrm{cm}$.
\end{abstract}

Keywords: spring coil sensor, Hartley oscillator, slope stability monitoring, landslide information

\section{Introduction}

A landslide is a complex geological phenomenon that involves movement of ground, rocks and soil under effect of gravity. Currently, landslide disaster often becomes a crucial problem which needs a reliable solution to diminish impact damage. Generally, a landslide can be triggered by several factors, such as geological (rainfall and climate change), physical (increased of surface soil), morphological, and human errors (activities, uncontrolled land-use, populations, growing urbanization and infrastructures) [1,2]. The occurrence of landslide can be monitored by several methods which are focused on monitoring slope movements. They are Tapes and GPS, extensometers, inclinometers, aerial photos, LiDAR (Light Detection and Ranging), satellite photos, InSAR (Interferometric Synthetic Aperture Radar). However, these methods have disadvantage limited on scale of area, instrumentation cost, difficult installation, and can't record the data for days or month [1].

The possible of the simplest methods of documenting landslide information is to install surface field monitoring tapes that can be sequentially measured for landslide movement [1]. Indicator of potential for slope movement can be assessed by observing the continuing movement which can aid in the characterization of the type of event [2]. This paper presents a novel development sensor for slope stability monitoring. A spring coil as an actuator for displacement sensor to evaluate the conditions of potential hazards and landslide. Spring coil has a long $1.2 \mathrm{~m}$, diameter $3 \mathrm{~cm}$, 80 turns and placed on above the ground. Electronic systems consist of an excitation, Hartley oscillator, comparator, filter, frequency to digital converter, and microcontroller. As a result, the sensor is work very good to indicate a potential slope movement and capable to be used as a displacement sensor for slope stability monitoring. The requirement of installation is relatively inexpensive.

\section{Self-Inductance of a Coil}

Spring coil (induction coil sensor) is a solenoid which has a long and thin coil [3]. If current $I$ flowing 
through a solenoid with $N$ turns, length $l$, and radius $R$ and applying Ampere's law, the magnetic field inside a solenoid is given by

$$
\vec{B}=\frac{\mu_{0} N I}{l} \hat{k}=\mu_{0} n I \hat{k}
$$

The magnetic flux through for each turn of the loop is $B \pi r^{2}=\mu_{0} N I \pi r^{2}$. The total flux through the solenoid which has $N$ and $l$ turns given by

$$
\Phi_{B}=N l \mu_{0} N I \pi r^{2}
$$

The self-inductance is defined as the induction of a voltage in a current-carrying wire when the current in the wire itself is changing. In this case, the magnetic field created by a changing current in the circuit itself induces a voltage in the same circuit. Therefore, the voltage is self-induced. Mathematically, the self-inductance of solenoid is

$$
L=\frac{N \Phi_{B}}{I}=\mu_{0} N^{2} \pi r^{2} l
$$

$L$ is a geometric quantity depending only on the dimensions of the solenoid, and the number of turns in the solenoid. Physically, the inductance $L$ is a measure of an inductor's "resistance" to the changing of the current, the larger the value of $L$, the lower the rate of change of current. The self-inductance of this sensor depends on the construction of the spring coil. Hartley oscillator circuit is used as sensor system which the changing of inductance on spring coil is become physical quantity that can be measured [3-5]. The output signal from LC oscillator is a frequency modulation (FM) which frequency is determined by

$$
f_{0}=\frac{1}{2 \pi \sqrt{L_{s} C_{s}}} \sqrt{1-R_{s}^{2} \frac{C_{s}}{L_{s}}}
$$

According to (4) the output signal depends linearly on frequency, but due to the internal self-capacitance $\mathrm{C}$ of the sensor, the dependence $\mathrm{V}=\mathrm{f}(\mathrm{f})$ is more complex. The equivalent electric circuit of sensor is shown in Figure 4.b [3].

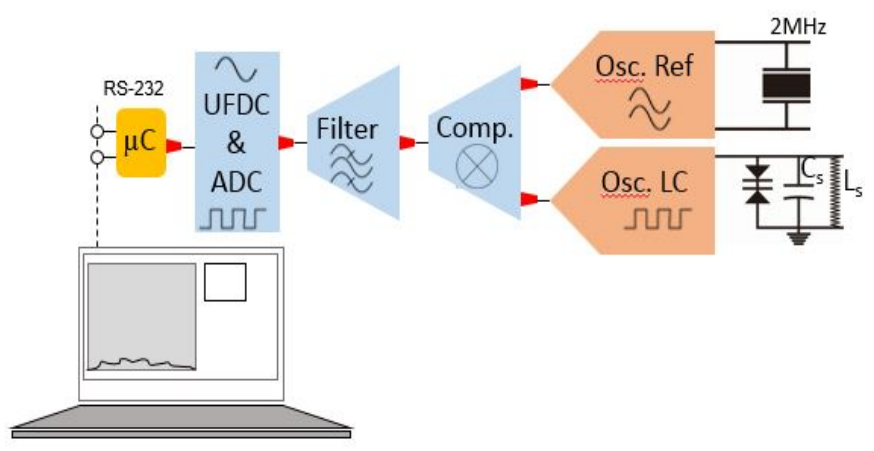

(a)

(2)

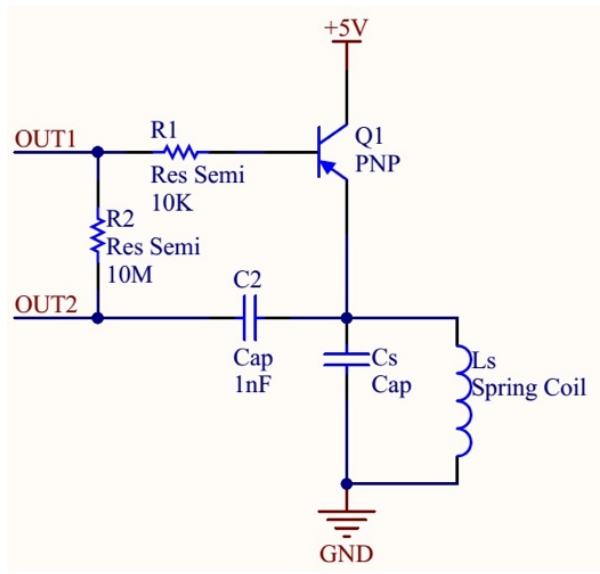

(b)

Fig. 1. (a) Block circuit diagram, (b) equivalent circuit

In Fig. 1(a), the system consists of a sensor system, a microcontroller, and a computer. The microcontroller has purpose for recording data from the sensor and sending to the computer. Block filter is used to reduce noise frequency output from the comparator. Then, the frequency will be converted to the digital level and processing to the computer. LC oscillator designed from an inductor (spring coil) $\mathrm{L}_{\mathrm{s}}$ and Capacitor $\mathrm{C}_{\mathrm{s}}$ as shown in the Figure 1(b). Pin OUT1 and OUT2 will be continued to IC4007 CMOS using discrete MOSFET transistor to produce a resonance frequency $\mathrm{LC}$. In order to produce frequency at $\mathrm{MHz}$, Capacitor $\mathrm{C}_{\mathrm{s}}$ has value $\mathrm{pF}$ (pico farad) and inductor $\mathrm{L}_{\mathrm{c}}$ (spring coil) has value $\mu \mathrm{H}$ (micro henry). Furthermore, Frequency from LC circuit will be compared with frequency reference $\left(f_{\text {ref }}\right)$, to obtain a stable square wave. The comparator has function for binding phase frequency oscillator against frequency reference. The spring coil actuator is shown in Figure 2. The resonance frequency of the oscillator is a function of distance. By using a phase locked loop (PLL) the changing of the resonance frequency is converted into voltage [4-5]. 


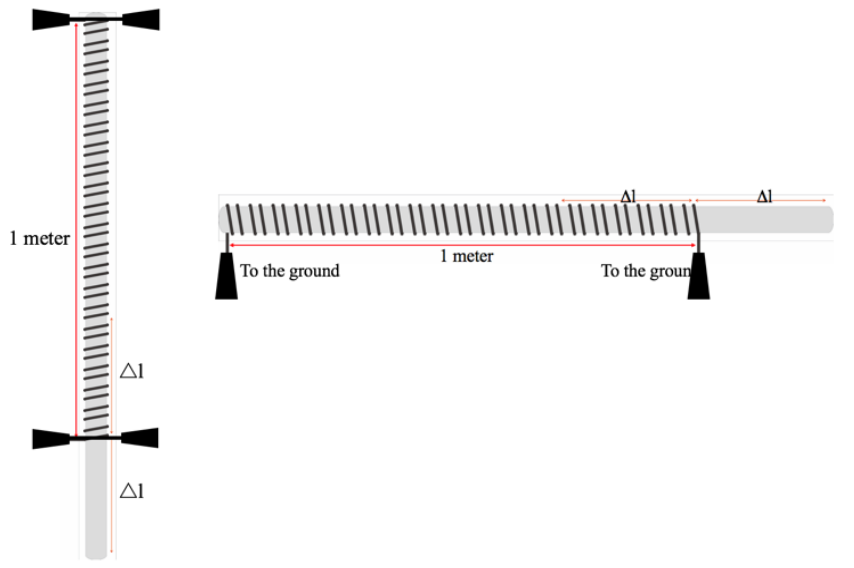

Fig. 2. The structure of spring coil actuator

In Fig. 2, the prototype of inductor was made from stainless steel with diameter $1 \mathrm{~mm}$. There are 2 types of tubes that is used to the direction and movement of spring coil. The outside tube acts a shield to protect the spring coil from the shock. The end of sensor will be installed $20 \mathrm{~cm}$ on underground. Each of end portion has a static and dynamic movement. This means that is only one portion can movement in two directions (forward and backward). This sensor is effective for measuring vibration and displacement.

\section{Characterization and Results}

A laboratory test was developed and designed in order to evaluate the ability of spring coil sensor. To comprehend the scale of inductance, sensor is moved on two directions (forward and backward). The characteristics of sensor is shown in Fig. 3.

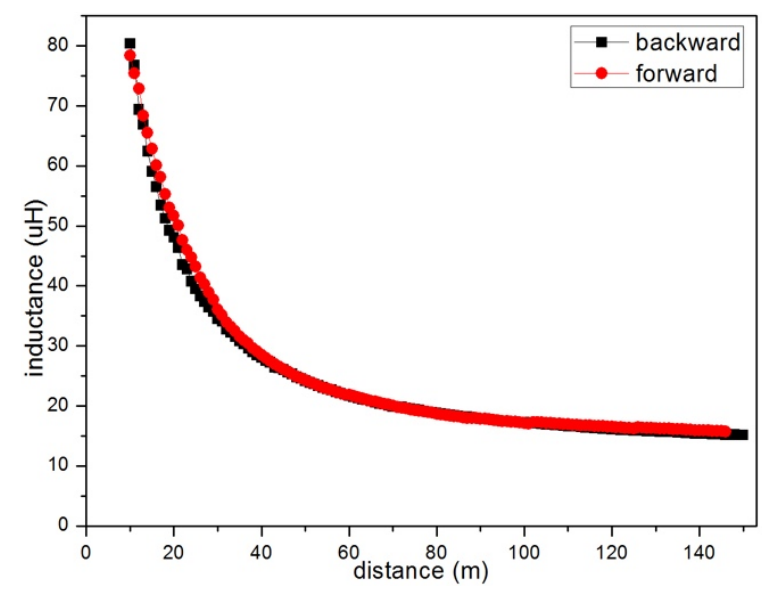

(a)

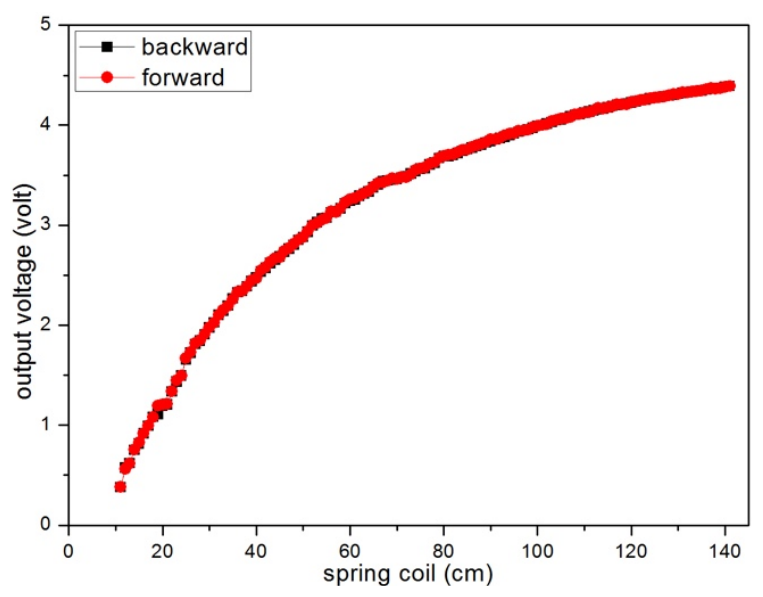

(b)

Fig. 3. (a) Characteristic spring coil as an actuator, (b) response of output sensor

Fig. 3(a) shows raw data from the sensor in evaluation test. As can be seen that the sensor has the same behavior while the spring coil is moved forward and backward. The output as a function of distance. This indicates that the sensor has capability as a displacement sensor. Fig. 3(b) shows the response of sensor output to a distance is neither compression nor strain. The output voltage and sensitivity sensor is inversely proportional to the distance range of sensor, due to the limited of sensor linear work area. This sensor is able to detect change in the distance of $3.125 \mathrm{mV} / \mathrm{mm}$.

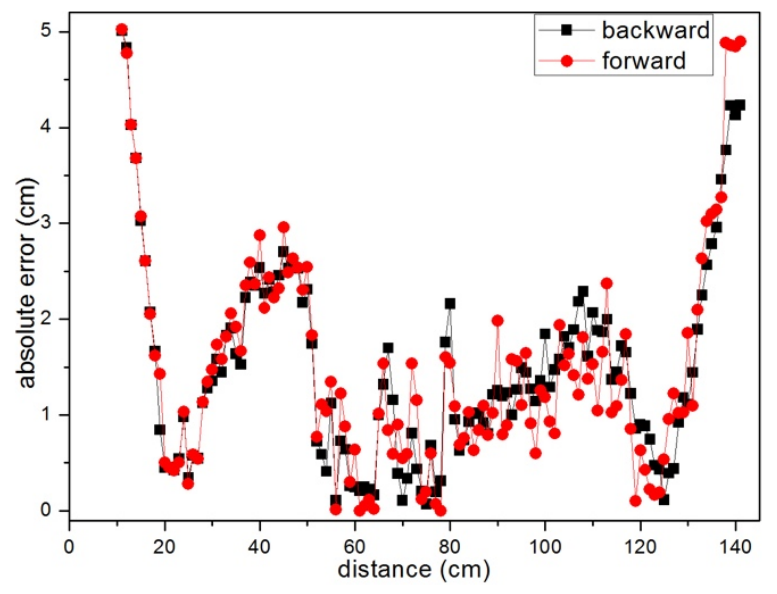

(a) 


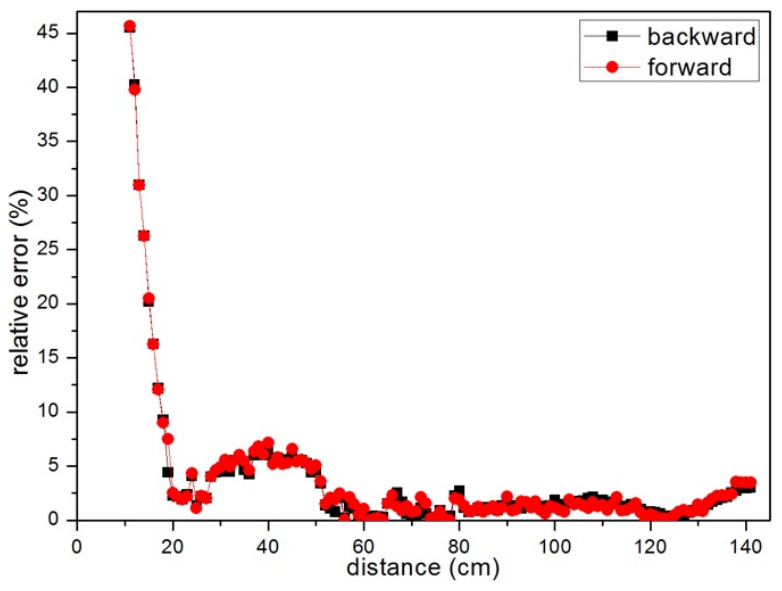

(b)

Fig. 4. (a) Absolute error, (b) relative error

Fig. 4(a) shows the absolute error of sensor. This shows that the sensor has the average of absolute error $2 \mathrm{~cm}$. However, at distance $20 \mathrm{~cm}$ and over $130 \mathrm{~cm}$, it has absolute error more than $3 \mathrm{~cm}$. Fig. 4(b) shows the sensor has the average of relative error under $3 \%$. However, on distance under $50 \mathrm{~cm}$, it has relative error more than $5 \%$. The relative error will be higher while the sensor is under high compression. Fig. 5 shows the profiles of slope monitoring during 5 days in simulation chamber. It can be seen that this sensor is able to measure a small displacement.

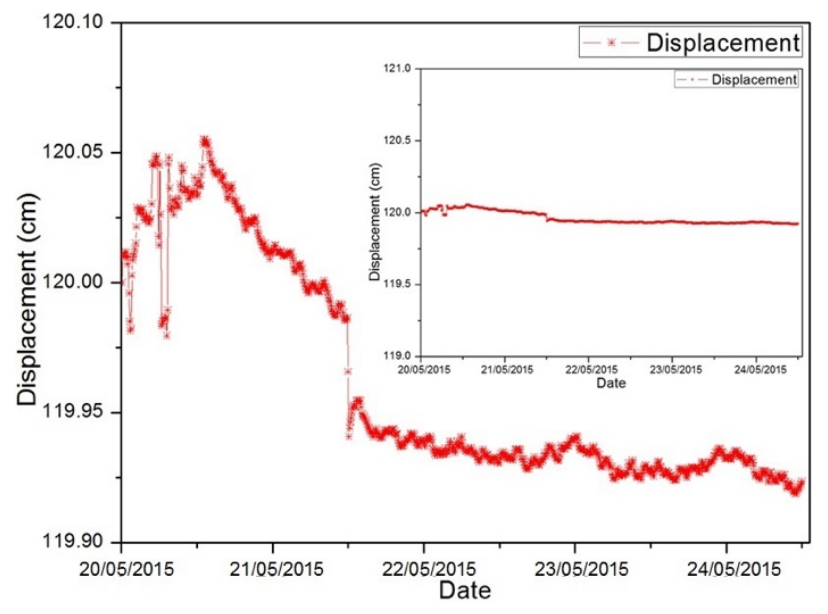

Fig. 5. Profiles of slope stability monitoring

\section{Conclusions}

A spring coil actuator have successfully developed and characterized for slope stability monitoring. A sensor system consists of Hartley oscillator, signal conditioning, microcontroller, and computer display. Spring coil was made from stainless steel with an along $1.2 \mathrm{~m}$, diameter
$1 \mathrm{~mm}$ and 80 turns. The inductance of spring coil will change when deformed (compression or strain). The raw data shows that the sensor has capability to measure low displacement the ground with the absolute error under $2 \mathrm{~cm}$ and the relative error under 3\%. Furthermore, the output and sensitivity sensor is inversely proportional to the distance and can detect changing of $3.125 \mathrm{mV} / \mathrm{mm}$. Further research is needed to optimize and develop a scale large sensor for slope stability monitoring which is capable to monitor a large area.

\section{Acknowledgment}

We would like to thanks to the ITB for supporting this research through Riset Inovasi KK 2016 with contract number $007 \mathrm{a} / 1 . \mathrm{C} 01 / \mathrm{PL} / 2016$ and to the Ministry of Research and Technology Directorate General of Higher Education through PUPT Grant 2016 with contract Nr. 586t/11.C01/PN/2016.

\section{References}

(1) G. F. Wieczorek, J. B. Snyder, "Monitoring Slope Movements", in Young, R., and Norby, L., Geological Monitoring: Boulder, Coloradio, Geological Society of America, 2009, pp. 245-271, DOI:10.1130/2009.monitoring(11).

(2) A. Zaki, H.K. Chai, H.A. Razak, T. Shiotani, "Monitoring and evaluating the stability of soil slopes A review on various available methods and feasibility of acoustic emission technique", C. R. Geoscience 346, 2014, pp. 223-232, DOI:10.1016/j.crte.2014.01.003.

(3) S. Tumanski, "Induction coil sensors-a review", Meas. Sci. Technol. 18, 2007, pp. R31R46,DOI:10.1088/0957-0233/18/3/R01.

(4) M. Djamal, Ramli, S. Satira and Suprijadi, "Development of a Low Cost Vibration Sensor Based on Flat Coil Element", International Journal of Mathematical Models and Methods in Applied Sciences, Issue 3, Vol. 5, 2010, pp. 550-557.

(5) E. Sanjaya, M. Djamal, Suprijadi, G. Handayani, A. Hartono, Ramli, "Development of Ground Displacement Sensor Based on Flat Coil Element for Detection of Landslide", IOSR Journal of Applied Physics (IOSR-JAP), Volume 6, Issue 1, Ver. III, 2014, pp. 01-06, DOI: 10.9790/486106130106 . 
(6) M. Mergili, I. Marchesini, M. Alvioli, M. Metz, B. Schneider-Muntau, M. Rossi, and F. Guzzetti, " $A$ Strategy for GIS-based 3-D slope stability modelling over large areas", Geosci. Model Dev., 7, 2014, pp. 2969-2982, DOI:10.5194/gmd-7-29692014.

(7) E. Intrieri, G. Gigli, F. Mugnai, R. Fanti, N. Casagli, "Design and implementation of a landslide early warning system", Engineering Geology 147148, 2012, pp. 124-136, DOI:10.1016/j.enggeo.2012.07.017.

(8) Y. Alimohammadlou, A. Najafi, A. Yalcin, "Landslide process and impacts: A proposed classification method", Catena 104, 2013, pp. 219232, DOI:10.1016/j.catena.2012.11.013.

(9) W. Zuoan, L. Shihai, J.G. Wang, and W. Ling, “ $A$ Dynamic comprehensive method for landslide control", Engineering Geology 84, 2006, pp. 1-11, DOI:10.101/j.enggeo.2005.09.019.

(10) A.B. Huang, J.T. Lee, Y.T. Ho, Y.F. Chiu, S.Y. Cheng, "Stability monitoring of rainfall-induced deep landslides through pore pressure profile measurements", Soils and Foundations 52(4), 2012, pp. 737-747, DOI:10.1016/j.sandf.2012.07.013.

(11) M. Djamal, S. Satira, "Sensor model of vibration sensor based on flat coil element", Mathematical Models for Engineering Science, 2010, pp. 77-81.

(12) L. Piccinini, M. Berti, A. Simoni, A.R. Bernardi, M. Ghirotti, A. Gargani, "Slope stability and groundwater flow system in the area of Lizzano in Belvedere (Northern Apennines, Italy)", Engineering Geology 183, 2014, pp. 276-289, DOI:10.1016/j.enggeo.2014.09.002. 